\title{
A STUDY OF CONGENITAL HEART DEFECTS IN MONGOLISM
}

\author{
BY \\ M. C. LIU and K. CORLETT \\ From the Fountain Hospital, London, S.W.17
}

(RECEIVED FOR PUBLICATION MARCH 11, 1959)

Mongolism has aroused widespread interest since the days of Langdon Down's pioneer work in 1866. Numerous hypotheses relating to its aetiology and mechanism have appeared, but none can be regarded as conclusive or final, further observations and research being necessary before a full understanding is possible.

Of the many anomalies found in mongolism, affecting nearly every system, that of congenital heart disease is the most remarkable and least understood, certainly, as Abbott (1936) stated, 'calling for an explanation'.

The life span of mongol children has already been extended by chemotherapy and antibiotics, and a further prolongation will follow the recent advances in cardiac surgery. For this reason congenital heart disease in mongols has ceased to be of mere postmortem interest and has become a stimulus to further understanding. The cause of the cardiac abnormality, the stage of foetal life at which it occurs and the pathological processes involved are problems of considerable interest which are difficult to solve.

Among the early observations were those of Abbott, who has stressed the frequent combination of mongolism and persistent ostium primum. Taussig (1947) emphasized the high correlation between mongolism and persistent atrioventricularis communis. Esen (1957) found a similar high correlation, but Evans (1950), in his study of cardiac anomalies in mongolism, showed a preponderance of ventricular and atrial septal defects. Benda (1946) stated that about $75 \%$ of mongoloid infants who die in the first two years of life have congenital heart disease, and $35 \%$ of the survivors thereafter. In Evans' series $50 \%$ died before 5 years of age. Keith, Rowe and Vlad (1958), in their study of 18 mongoloid infants who died at the Hospital for Sick Children, Toronto, mentioned that few die in the first month of life, and two-thirds die between 4 weeks and 1 year. On clinical evidence, those with the most severe cardiac anomalies die young, and so, as the age group progresses, the incidence of severe cardiac anomaly becomes less. This largely accounts for the comparatively low incidence found by other observers. This point is well illustrated in the two different age groups studied at the Fountain Hospital, the percentage of cardiac anomalies in the 3-year age group being much higher than that in the 10-year group.

Southwick (1939) and Ingalls (1947) were interested in the causation and time of origin of the cardiac anomalies. Ingalls postulated that the latter was between the sixth and ninth week of foetal life. This hypothesis has been well supported by many pathologists from necropsy material as well as from embryological evidence. The higher incidence, about to be discussed, of maternal illness in the early part of pregnancy in the congenital heart defect group than in the control group, suggests that the time of development of the anomalies must be early. The frequent combination of congenital heart defect and mongolism suggests that the cause and time of development of congenital heart defect are similar to, if not identical with, that of mongolism as a whole.

Among the many factors involved in the aetiology of mongolism, advanced maternal age (Davenport and Allen, 1925; Penrose, 1934; Bleyer, 1938), and maternal illness (Ingalls, Babbott and Philbrook, 1957) are considered here. Engler (1949) stressed the influence of an unfavourable intrauterine environment. Maternal rubella as a cause of congenital heart defect was mentioned by Gregg (1941) and Swan, Tostevin, Moore, Mayo and Black (1943). So far rubella has not been recorded in the literature as a cause of congenital heart defect in mongolism.

\section{Present Study}

The present work is an attempt to assess the incidence, aetiology and type of congenital heart defect in 216 mongoloid imbeciles admitted to the Fountain Hospital in the 14 years between Septem- 
ber, 1944, and July, 1958. It is based on social and clinical assessments and, in some cases, on autopsy findings. Forty-three cases have been discharged and excluded from this survey and 51 died, leaving a total of 122 children, whose mean age was 10 years, still in the hospital. Eleven of the 122 cases had a congenital heart defect, the diagnosis being made on the clinical history, physical findings and radiological and cardiological investigations. In another 17 cases, a variable soft precordial systolic murmur had been reported during earlier life, but in only seven of these was it present at the time of investigation; radiology then revealed a heart of normal size and shape and the electrocardiogram was normal. An analysis of the findings in the 111 children with normal hearts is given in Table 1 .

In nine of the 11 cases with congenital heart defect cardiac catheterization, cine angiography and other necessary investigations were carried out in the cardiac department of St. George's Hospital. The following case reports illustrate the two more frequent types of cardiac anomaly.

Case 2 (Table 2). B.J., a mongol girl, was born on August 20, 1945, of normal intelligent parents, the father aged 40 and the mother 39 years at the birth. This was the mother's fourth pregnancy, the second resulting in a stillbirth due to malpresentation, the first and third producing children of normal health and intelligence. The mother's health was good during this pregnancy and the birth was rapid. The birthweight was $8.5 \mathrm{lb}$. There was no unusual neonatal history and mongolism was diagnosed at birth.

The child was admitted to the Fountain Hospital aged $6 \frac{1}{2}$ years. She had all the usual mongoloid characteristics with a shy, docile and co-operative temperament. Her speech was poor and her I.Q. was 30 on the StanfordBinet (T.M. Rev.) Form L. She had repeated attacks of respiratory illness each year; during these her peripheral circulation, never very good, was poor and her extremities became cold and cyanotic. She was breathless on exertion but there was no evidence of heart failure. The femoral pulses were present and her B.P. was $115 / 70$. An ejection systolic murmur and a fixed splitting of the second sound were heard over the pulmonary area. Radiography suggested a right heart enlargement. The electrocardiogram showed an rsR pattern in $V_{1}$ and an atrial septal defect was diagnosed and confirmed by cardiac catheterization.

Case 5. L.P., a boy 9 years old, was born on August 26,1948 , the mother's age being 43 , the father's 42 years at the birth. He was the second child, the first being a girl of average intelligence. The pregnancy and birth were said to have been normal. The birthweight was $8.5 \mathrm{lb}$. There was no unusual neonatal history except

TABLE 1

AN ANALYSIS OF 111 MONGOLS WITH NORMAL HEARTS

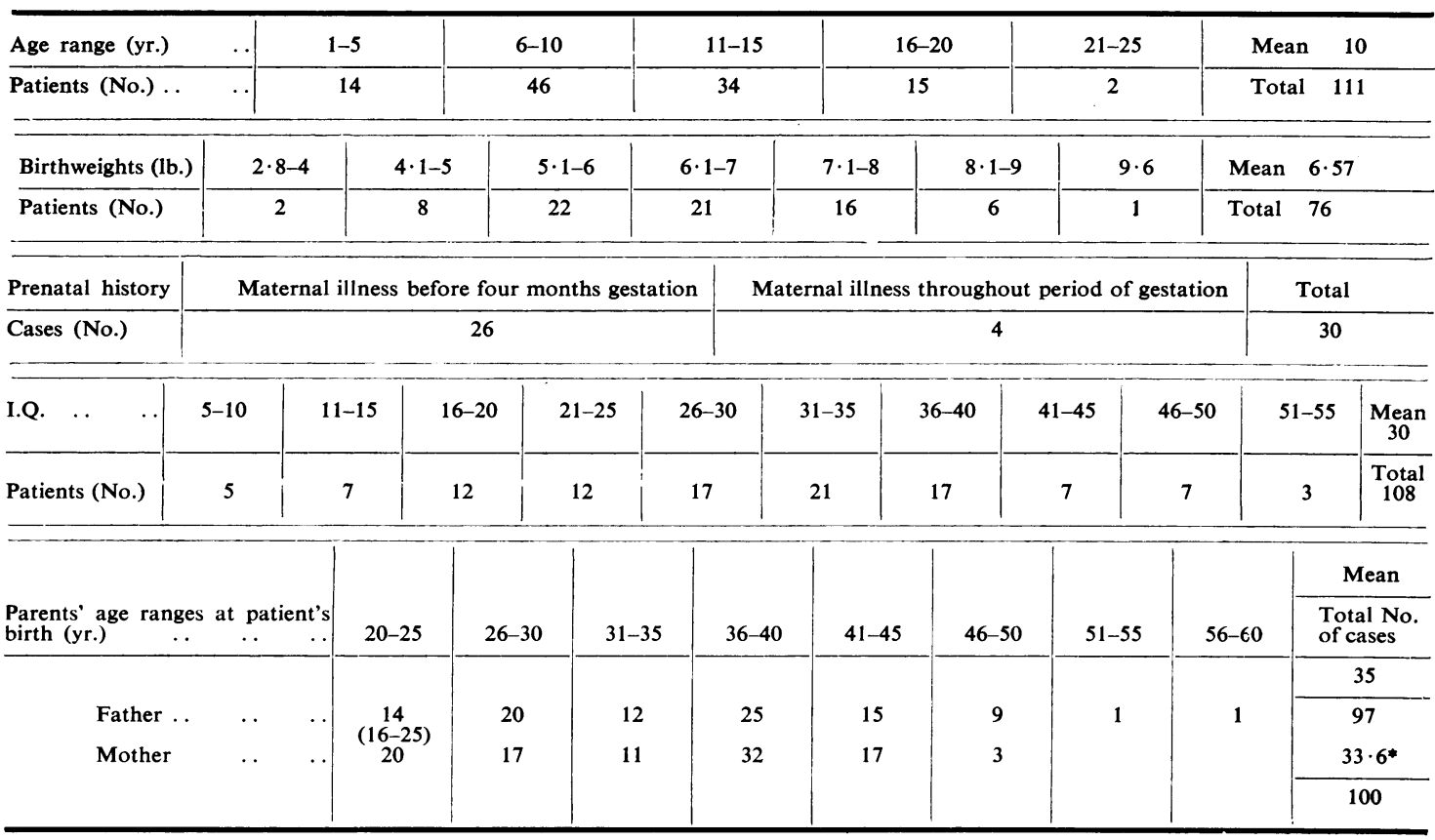

* Ages are calculated in decimals in all Tables to facilitate statistical analysis. 
CLINICAL DETAILS OF 11 MONGQ్S

\begin{tabular}{|c|c|c|c|c|c|c|c|c|c|c|c|}
\hline \multirow{2}{*}{ Case No. } & \multirow{2}{*}{ Age (yr.) } & \multirow{2}{*}{ Sex } & \multicolumn{2}{|l|}{ History } & \multirow{2}{*}{$\begin{array}{c}\text { Birth- } \\
\text { weight } \\
\text { (lb.) }\end{array}$} & \multirow[b]{2}{*}{ 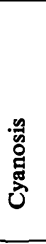 } & \multirow{2}{*}{$\begin{array}{l}\stackrel{\Xi}{0} \\
\stackrel{0}{0} \\
\stackrel{0}{0}\end{array}$} & \multirow{2}{*}{ 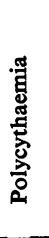 } & \multicolumn{2}{|c|}{$\begin{array}{l}\text { Cardiac } \\
\text { Murmurs }\end{array}$} & \multirow{2}{*}{ Radiology } \\
\hline & & & Prenatal & Neonatal & & & & & Types & $\begin{array}{c}\text { First } \\
\text { detected } \\
\text { (yr.) }\end{array}$ & \\
\hline 1 & $10 \cdot 2$ & $\mathbf{F}$ & Haemorrhage & Cyanosed & $9 \cdot 0$ & - & - & - & S.M. & At birth & $\begin{array}{l}\text { Heart enlarged; } \\
\text { globular shaped }\end{array}$ \\
\hline 2 & $12 \cdot 9$ & $\mathbf{F}$ & $\mathbf{N}$ & $\mathbf{N}$ & $8 \cdot 5$ & - & - & - & S.M. & $6 \cdot 5$ & Rt. heart sl. enlarged \\
\hline 3 & 16.9 & $\mathbf{F}$ & $\mathbf{N}$ & Cyanosed & $7 \cdot 25$ & - & - & - & S.M. & At birth & $\begin{array}{ll}\text { Heart enlarged } & \text { ㅇํㅇ } \\
& \end{array}$ \\
\hline 4 & $18 \cdot 3$ & $\mathbf{F}$ & Hyperemesis gravidarum & Jaundiced & $5 \cdot 5$ & + & + & + & S.M. & 2 & $\begin{array}{l}\text { R.V.++ + bronchp } \\
\text { ectasis }\end{array}$ \\
\hline 5 & $9 \cdot 9$ & $\mathbf{M}$ & $\mathbf{N}$ & $\mathbf{N}$ & $8 \cdot 5$ & - & - & - & S.M. & At birth & $\begin{array}{l}\text { Globular heart; } \\
\text { pulm. plethora } \\
\end{array}$ \\
\hline 6 & $13 \cdot 3$ & $\mathbf{F}$ & $\mathbf{N}$ & Jaundiced & $7 \cdot 0$ & - & - & - & S.M. & At birth & $\begin{array}{l}\text { Heart prominent } Q \mathrm{t} \text {. } \\
\text { border }\end{array}$ \\
\hline 7 & $17 \cdot 3$ & $\mathbf{F}$ & $\mathbf{N}$ & $\begin{array}{l}\text { Difficult } \\
\text { sucking }\end{array}$ & $7 \cdot 0$ & - & - & - & S.M. & 11 & $\begin{array}{l}\text { Enlarged heart; } \\
\text { R.A.++; pulm } \\
\text { plethora }\end{array}$ \\
\hline 8 & $5 \cdot 9$ & $\mathbf{M}$ & $\mathbf{N}$ & $\begin{array}{l}\text { Jaundiced; } \\
\text { difficult } \\
\text { sucking }\end{array}$ & $8 \cdot 0$ & + & + & - & S.M. & 4 & $\begin{array}{l}\text { Enlarged heart; pu晦. } \\
\text { plethora }\end{array}$ \\
\hline 9 & $4 \cdot 5$ & $\mathbf{M}$ & $\mathbf{N}$ & $\begin{array}{l}\text { Cyanosed; } \\
\text { difficult } \\
\text { sucking }\end{array}$ & $6 \cdot 0$ & - & - & - & S.M. & At birth & Rt. heart engrefta \\
\hline 10 & $2 \cdot 0$ & $\mathbf{M}$ & $\mathbf{N}$ & $\begin{array}{l}\text { Cyanosed; } \\
\text { difficult } \\
\text { sucking }\end{array}$ & $6 \cdot 8$ & + & - & - & S.M. & At birth & Heart round sị \\
\hline 11 & $11 \cdot 8$ & $\mathbf{F}$ & Show $4 \mathrm{mth}$. & $\mathbf{N}$ & $\begin{array}{c}8 \cdot 1 \\
.\end{array}$ & + & + & + & S.M. & $3 \cdot 7$ & $\begin{array}{l}\text { Heart enlarged; } \\
\text { bronchiectasis }\end{array}$ \\
\hline Mean & $11 \cdot 2$ & & & & $7 \cdot 4$ & & & & & & $\frac{\overline{0}}{3}$ \\
\hline
\end{tabular}

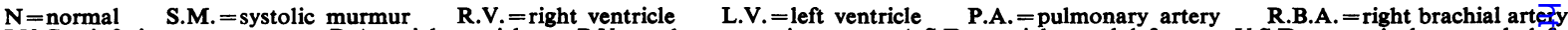

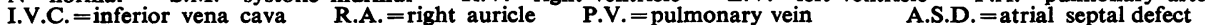
= ventricular septal defect P.S.=pulmonary stenosis

that a cardiac murmur was heard when he was 1 week old. He suffered from bronchitis, pneumonia and meningococcal meningitis in infancy. However, his general health has gradually improved since admission to this hospital aged 2 years 10 months, and at present he enjoys better health than most of his fellow patients. $\mathrm{He}$ is a pleasant, co-operative boy. His I.Q. was 31 on the Stanford-Binet Scale (T.M. Rev.) Form L. On examination he appeared to be in good general health with a good peripheral circulation and no signs of heart strain. The radial pulses were strong and full, with a rate of 82 per minute, and the B.P. was 120/80. A loud systolic murmur was heard at the apex. Radiography revealed a slightly globular-shaped heart, and the electrocardiogram was within normal limits. Both cardiac catheterization and selective cine angiography demonstrated a left to right shunt at ventricular level, and a ventricular septal defect was diagnosed.
Autopsy Cases. Among the 51 patients who died, autopsies were performed on 44, of whom 16 had congenital heart defects (Table 3). Six patients had patent foramen ovale and were not included in the number of those with congenital anomalies, leaving a total of 22 in whom autopsy showed a normal heart. Table 4 illustrates the causes of death of the latter.

The tentative diagnosis of congenital heart defect was initially based on clinical examination (e.g. cardiac murmurs, cyanosis, etc.). There were six patients with cardiac anomalies which had not been detected during life. Possible reasons for this include the observers' inexperience, difficulty in examination owing to an unco-operative patient, lack of full examination, murmurs not being present 


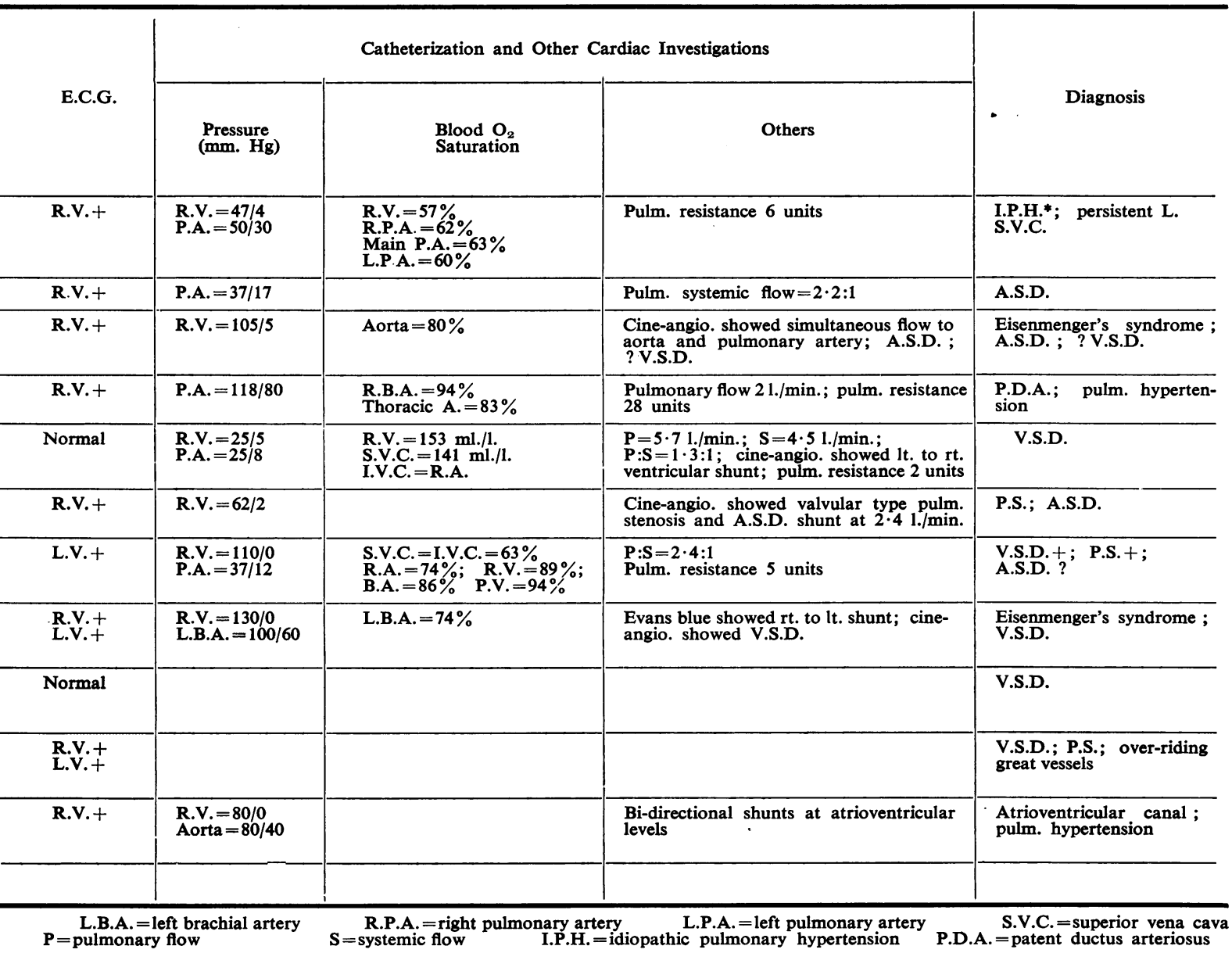

at the time, excessive noise in the thoracic cavity, pulmonary infection and pericardial effusion. (There were two cases of pericardial effusion containing more than $100 \mathrm{ml}$. of straw-coloured fluid.) A comparison was made of the types of cardiac anomalies diagnosed on clinical grounds and at autopsy and is summarized in Tables 2, 3 and 6.

An analysis of the various types of lesions showed that ventricular septal defect was the most common and occurred in 10 cases, of which six were in the clinical group. Atrial septal defect was the next most frequent, a total of eight cases, four of which were in the clinical group. Patent ductus arteriosus was the third most frequent, occurring in seven cases, of which six were in the autopsy group. Vessel anomalies occurred in four cases and were equally distributed in both groups. Pulmonary stenosis occurred in three cases of the clinical group and none in the autopsy group. Atrioventricularis communis occurred in three instances, Fallot's tetralogy, Eisenmenger's syndrome and valvular anomalies each occurred in two instances. Other rare defects had the same frequency; idiopathic pulmonary hypertension occurred in one case only in the clinical group.

Associated anomalies of the general systemic organs may be as numerous and variable as the outward manifestations of mongolism, and a comparative study of their relative development in time would lead towards an understanding of both the stage of foetal life at which cardiac anomalies occur and their aetiology. Unfortunately, such a study 
has not been possible with the records available for discussion in this paper.

Cause of Death. The high mortality rate in children with congenital heart defect has been reduced recently by the introduction of chemotherapeutic and antibiotic drugs. More recently still, advances in cardio-surgical techniques have led to the promise of a completely new outlook.

The major cause of death in this series was chest infection, chiefly bronchopneumonia. The high incidence of cardiac complications in the congenital heart defect group is worth mentioning. Two cases had pericardial effusion, one had infective endo- carditis and another cerebral embolism. From the study of these cases it seems obvious that if the condition were recognized early enough, precautions against current infections could be taken or special surgical measures could be provided, enabling most of these complications to be prevented or treated.

Mean Age of Death. The mean age at death of the congenital heart defect group is $3 \cdot 2$ years, and that of the mongols without congenital heart defect is 3.3 years (Tables 3 and 4 ). These figures are almost identical, and the difference is probably too small to be of any statistical significance (not including

TABLE 4

CLINICAL DETAILS AND AUTOPSY FINDINGS IN 22 MONGOLS WITH NORMAL HEARTS

\begin{tabular}{|c|c|c|c|c|c|c|c|c|c|c|c|c|}
\hline \multirow{3}{*}{$\begin{array}{l}\text { Case } \\
\text { No. }\end{array}$} & \multirow{3}{*}{$\begin{array}{c}\text { Age } \\
(\text { Yr. })\end{array}$} & \multirow{3}{*}{ Sex } & \multicolumn{2}{|c|}{ History } & \multirow{3}{*}{$\begin{array}{l}\text { B.W. } \\
\text { (lb.) }\end{array}$} & \multirow{3}{*}{ B.R. } & \multirow{3}{*}{ I.Q. } & \multirow{2}{*}{\multicolumn{2}{|c|}{$\begin{array}{l}\text { Age at } \\
\text { Patient's } \\
\text { Birth (yr.) }\end{array}$}} & \multicolumn{2}{|c|}{ At Death } & \multirow{3}{*}{ Cause of Death } \\
\hline & & & & & & & & & & \multirow{2}{*}{$\begin{array}{l}\text { Wt. } \\
\text { (lb.) }\end{array}$} & \multirow{2}{*}{$\begin{array}{l}\text { Ht. } \\
\text { (in.) }\end{array}$} & \\
\hline & & & Prenatal & Neonatal & & & & M. & F. & & & \\
\hline a. 17 & $3 \cdot 0$ & $\mathbf{F}$ & & & & 1 & 56 & 20 & & $22 \cdot 5$ & 33 & Bronchopneumonia \\
\hline a. 18 & $4 \cdot 3$ & $\mathbf{M}$ & $\begin{array}{c}\text { Familial } \\
\text { poor health }\end{array}$ & & & 3 & & 41 & 41 & $29 \cdot 8$ & & Acute bronchitis \\
\hline a.19 & $2 \cdot 7$ & $\mathbf{F}$ & $\mathbf{N}$ & $\mathbf{N}$ & $8 \cdot 5$ & 2 & 21 & 28 & 30 & 21 & & Bronchopneumonia; gastro-enteritis \\
\hline a.20 & $2 \cdot 5$ & $\mathbf{M}$ & $\mathbf{N}$ & $\mathbf{N}$ & $7 \cdot 1$ & 3 & 23 & 25 & 22 & 25 & & $\begin{array}{l}\text { Otitis media; cerebral oedema; conges- } \\
\text { tion of lungs; pyonephrosis (one kidney } \\
\text { only) }\end{array}$ \\
\hline a.21 & $4 \cdot 3$ & $\mathbf{M}$ & $\mathbf{N}$ & $N^{*}$ & $5 \cdot 0$ & 1 & 10 & 25 & 26 & 28 & 42 & Inhalation pneumonia; renal haemorrhage \\
\hline a.22 & $1 \cdot 3$ & $\mathbf{F}$ & & & & 2 & & & & 24 & 29 & Bronchopneumonia \\
\hline a.23 & $0 \cdot 9$ & $\mathbf{M}$ & $\mathbf{N}$ & $\mathbf{N}$ & ! & 3 & 33 & 37 & 38 & 14 & & Bronchopneumonia \\
\hline a. 24 & $2 \cdot 4$ & $\mathbf{M}$ & $\mathbf{N}$ & $\mathbf{N}$ & $6 \cdot 8$ & & & 36 & 41 & 30 & 35 & $\begin{array}{l}\text { Peritonitis; perforation of Meckel's } \\
\text { diverticulum }\end{array}$ \\
\hline a.25 & $3 \cdot 8$ & $\mathbf{M}$ & $\mathbf{N}$ & $\mathbf{N}$ & $6 \cdot 0$ & 9 & 31 & 46 & 50 & $31 \cdot 5$ & & Acute laryngotracheo-bronchitis \\
\hline a.26 & $2 \cdot 9$ & $\mathbf{M}$ & & & $4 \cdot 8$ & 1 & 50 & 25 & 40 & 17 & 30 & $\begin{array}{l}\text { Bronchopneumonia; thrombocytopenic } \\
\text { purpura }\end{array}$ \\
\hline a. 27 & $9 \cdot 0$ & $\mathbf{M}$ & & & $7 \cdot 0$ & 2 & 24 & 39 & 38 & 51 & & Purulent bronchitis; measles \\
\hline a. 28 & $3 \cdot 8$ & $\mathbf{M}$ & $\mathbf{N}$ & $\mathbf{N}$ & $5 \cdot 2$ & 1 & 27 & 39 & 41 & 20 & 30 & Bronchopneumonia \\
\hline a.29 & $5 \cdot 3$ & $\mathbf{F}$ & $\mathbf{N}$ & $\mathbf{N}$ & & 3 & 20 & 35 & 34 & $26 \cdot 5$ & $36 \cdot 5$ & Acute bronchitis \\
\hline a. 30 & $4 \cdot 3$ & $\mathbf{F}$ & $\mathbf{N}$ & $\mathbf{N}$ & $7 \cdot 0$ & 7 & 19 & 48 & 30 & 18 & 34 & Bronchopneumonia \\
\hline a. 31 & $3 \cdot 2$ & $\mathbf{F}$ & & & & & 26 & & & 24 & 34 & Bronchopneumonia \\
\hline a. 32 & $3 \cdot 5$ & $\mathbf{M}$ & $\begin{array}{l}\text { Swollen } \\
\text { ankles }\end{array}$ & & $7 \cdot 0$ & 3 & 9 & 38 & 39 & $11 \cdot 5$ & 30 & Bronchopneumonia; hydronephrosis \\
\hline a.33 & $2 \cdot 0$ & $\mathbf{M}$ & $\begin{array}{l}\text { Poor health } \\
\text { Fainting }\end{array}$ & * & & 3 & 42 & 26 & 34 & 28 & $29 \cdot 5$ & Bronchopneumonia \\
\hline a. 34 & $1 \cdot 6$ & $\mathbf{F}$ & $\mathbf{N}$ & $\mathbf{N}$ & & 3 & 55 & 32 & 42 & $2 \cdot 1$ & 34 & Otitis media; pulmonary collapse \\
\hline a.35 & $2 \cdot 5$ & $\mathbf{F}$ & & & & & 36 & 37 & & $26 \cdot 5$ & & Bronchopneumonia \\
\hline a.36 & $5 \cdot 6$ & & $\mathbf{N}$ & $\mathbf{N}$ & $7 \cdot 6$ & 4 & 44 & 41 & 41 & 35 & 39 & Bronchopneumonia \\
\hline a. 37 & $3 \cdot 2$ & $\mathbf{M}$ & & & $6 \cdot 0$ & 3 & 26 & 23 & 25 & 22 & 34 & Lobar pneumonia \\
\hline a. 38 & $1 \cdot 3$ & $\mathbf{M}$ & & & & 2 & & 25 & & 18 & 29 & Acute tracheobronchitis \\
\hline Mean & $3 \cdot 3$ & & & & $6 \cdot 5$ & $2 \cdot 9$ & 31 & $34 \cdot 4$ & $37 \cdot 2$ & $24 \cdot 7$ & $33 \cdot 3$ & \\
\hline
\end{tabular}

* Premature. 
Case a.7). Experience suggests that after the first year of life, mongols with congenital heart defect have an equal chance of survival with those having a normal cardiovascular system.

Ingalls, as already mentioned, was of the opinion that the cause of mongolism operates before the end of the third month of foetal life and it is generally believed that the processes leading to the associated cardiac defects originate during the same period. This being accepted, a knowledge of early foetal environment might throw considerable light on the aetiology of these defects, but unfortunately little objective information of importance is available in most cases. However, since mongolism is of overriding importance to the mother compared with her reaction to the presence of congenital heart defect in her mongol child, it is felt that information obtained from her concerning her health during pregnancy might lead to the recognition of significant differences between the foetal environment in cases with and without congenital heart defect. The following information includes, therefore, a social history as well as points from hospital reports where these are available.

For the purpose of analysis, special emphasis is placed on the following aspects of prenatal history.

Parental Age (Tables 1 and 3-5). The mean age of the fathers at the birth of the 111 patients without congenital heart defect was 35 years, and that of the mothers 33.6 years. The mean age of the fathers for the 11 clinically diagnosed congenital heart defect cases was 36.7 years and that of the mothers was 34.5 years, the controls being 34.9 and 34 for the fathers and mothers respectively. Those for the autopsied congenital heart defect group were 36 years and 33 years, and for the group with normal hearts, 37.2 years and 34.4 years for fathers and mothers respectively. All these results showed no appreciable difference between the various groups.

Maternal Illness. This was recorded in three instances in the 11 clinical cases of congenital heart defect: for instance, in Case 1 (Table 2) there was a history of haemorrhage at two months of gestation which lasted four weeks. In Case 4, maternal 'ill-health' and sickness and excessive worry persisted throughout the pregnancy, and in Case 11 there was a history of vaginal bleeding before the fourth month of gestation.

Among the 16 autopsy cases with congenital heart defect (Table 3) there were 11 with a history of maternal illness, and where possible a definite date has been shown. One had amoebic dysentery and developed a liver abscess at the third month of pregnancy. She also suffered from severe anaemia. In the second case, the mother had a bad fall at the third month of gestation. Three cases suffered from 'ill-health' and one of these had hydramnios. In Case a.8 the mother had pleurisy during the first three months of pregnancy; in Case a.9 she had a threatened miscarriage at the third month; in Case a.12 she suffered from 'ill-health' and swelling of the legs; in Case a.14 she had high blood pressure, in Case a.15 venereal disease and in Case a.16 the mother was very ill with tertian malaria. She had a 'stroke' (details unknown) with vomiting and haemorrhage.

Maternal illness affected only 30 of the 111 mothers (Table 1) whose infants had no congenital heart defect. Twenty-six of these occurred before the fourth month of pregnancy. A few were unwell throughout. The nature of the illnesses more or less followed the same pattern as those mentioned above. These were haemorrhage in eight, symptoms of 'toxaemia' in eight, feverish illnesses in five, trauma in five, attempted abortion in four, and a history of shock and previous miscarriages in three. These give a total incidence of $51 \cdot 5^{\circ}$ o (14/27) of maternal illness in early pregnancy in the congenital heart defect group, and $27^{\circ} \%(30 / 111)$ in the group with normal hearts. These differences are statistically significant $\left(\chi^{2}=6 \cdot 16, P 0 \cdot 02 \Leftarrow>0.01 \mathrm{dfi}\right.$. $)$.

Prematurity. This was present in 13 cases $\left(11 \cdot 7^{\circ}, o\right)$ in the group with normal hearts. Among the 22 autopsied patients with normal hearts (Table 4) two had a history of prematurity. Case a.21 was six to seven weeks premature and the birthweight was $5 \mathrm{lb}$. Case a.33 resulted from an eight months' gestation, the birthweight not being recorded. There was no instance of prematurity among the 11 clinically diagnosed cases of congenital heart defect (Table 2). Of the 16 autopsied cases with congenital heart defect, prematurity was mentioned in Case a.6, but the birthweight was $8 \mathrm{lb}$. (Table 3) and prematurity was therefore excluded.

Birth Rank. This was compared in the two groups. Table 5 shows 3.4 for the congenital heart defect group and 2.9 for the control group, while Tables 3 and 4 show $2 \cdot 8$ for the congenital heart defect group and 2.9 for the group with normal hearts.

Neonatal History. In Table 5 the neonatal history of the 11 clinical cases of congenital heart defect is compared with 11 controls consisting of mongoloid patients with normal hearts, their ages and sexes being matched as closely as possible. Four of the congenital heart defect group were cyanosed 
TABLE 5

A COMPARISON OF 22 MONGOLS, 11 WITH AND 11 WITHOUT CONGENITAL CARDIAC DEFECTS

\begin{tabular}{|c|c|c|c|c|c|c|c|c|c|c|c|}
\hline \multirow[b]{3}{*}{ Case No } & \multirow[b]{3}{*}{ Age (Yr.) } & \multirow[b]{3}{*}{ Sex } & \multirow[b]{3}{*}{ Birth Rank } & \multicolumn{4}{|c|}{ Mongolism with C.H.D. } & \multirow[b]{3}{*}{ Wt. (lb.) } & \multirow[b]{3}{*}{ Ht. (in.) } & \multirow{2}{*}{\multicolumn{2}{|c|}{ Parents' Age }} \\
\hline & & & & \multirow[b]{2}{*}{$\begin{array}{l}\text { Birth Wt. } \\
\text { (lb.) }\end{array}$} & \multicolumn{2}{|c|}{ History } & \multirow[b]{2}{*}{ I.Q. } & & & & \\
\hline & & & & & Prenatal & Neonatal & & & & Mother & Father \\
\hline 1 & $10 \cdot 2$ & $\mathbf{F}$ & 3 & $9 \cdot 0$ & $\begin{array}{l}\text { Haemorrhage } \\
2 \mathrm{mth} .\end{array}$ & Cyanosed & 32 & $42 \cdot 7$ & $46 \cdot 5$ & 35 & 35 \\
\hline 2 & $12 \cdot 9$ & $\mathbf{F}$ & 4 & $8 \cdot 5$ & $\mathbf{N}$ & $\mathbf{N}$ & 30 & $56 \cdot 8$ & $49 \cdot 0$ & 39 & 40 \\
\hline 3 & $16 \cdot 9$ & $F$ & 1 & $7 \cdot 25$ & $\mathbf{N}$ & Cyanosed & 28 & $126 \cdot 1$ & $55 \cdot 8$ & 34 & 41 \\
\hline 4 & $18 \cdot 3$ & $\mathbf{F}$ & 1 & $5 \cdot 5$ & Familial & Jaundiced & 42 & $98 \cdot 6$ & $57 \cdot 5$ & 20 & 19 \\
\hline 5 & $9 \cdot 9$ & $\mathbf{M}$ & 2 & $8 \cdot 5$ & $\mathbf{N}$ & $\mathbf{N}$ & 31 & $70 \cdot 3$ & $52 \cdot 0$ & 43 & 42 \\
\hline 6 & $13 \cdot 3$ & $F$ & 5 & $7 \cdot 0$ & $\mathbf{N}$ & Jaundiced & 32 & $64 \cdot 3$ & $49 \cdot 5$ & 34 & 39 \\
\hline 7 & $17 \cdot 3$ & $\mathbf{F}$ & 6 & $7 \cdot 0$ & $\mathbf{N}$ & $\begin{array}{l}\text { Sucking } \\
\text { difficulty }\end{array}$ & 22 & $84 \cdot 8$ & $55 \cdot 5$ & 44 & 43 \\
\hline 8 & $5 \cdot 9$ & $\mathbf{M}$ & 4 & $8 \cdot 0$ & $\mathbf{N}$ & $\begin{array}{l}\text { Sucking } \\
\text { difficulty. } \\
\text { Jaundiced }\end{array}$ & 40 & $42 \cdot 1$ & $36 \cdot 5$ & 32 & 36 \\
\hline 9 & $4 \cdot 5$ & $\mathbf{M}$ & 4 & $6 \cdot 0$ & $\mathbf{N}$ & $\begin{array}{l}\text { Sucking } \\
\text { difficulty. } \\
\text { Cyanosed }\end{array}$ & 25 & $28 \cdot 4$ & $32 \cdot 5$ & 30 & 27 \\
\hline 10 & $2 \cdot 0$ & $\mathbf{M}$ & 4 & $6 \cdot 8$ & $\mathbf{N}$ & $\begin{array}{l}\text { Sucking } \\
\text { difficulty. } \\
\text { Cyanosed }\end{array}$ & 21 & $14 \cdot 3$ & $24 \cdot 4$ & 28 & 29 \\
\hline 11 & $11 \cdot 8$ & $\mathbf{F}$ & 3 & $8 \cdot 1$ & Show $4 \mathrm{mth}$. & $\mathbf{N}$ & 36 & $56 \cdot 1$ & $49 \cdot 3$ & 41 & 53 \\
\hline Mean & $11 \cdot 2$ & & $3 \cdot 4$ & $7 \cdot 4$ & & & $30 \cdot 8$ & $67 \cdot 6$ & $47 \cdot 5$ & $34 \cdot 5$ & $36 \cdot 7$ \\
\hline & & & & Mon & golism without & C.H.D. & & & & & \\
\hline 1 & $9 \cdot 8$ & $\mathrm{~F}$ & 3 & $7 \cdot 2$ & $\mathbf{N}$ & $\mathbf{N}$ & 18 & $56 \cdot 6$ & $48 \cdot 5$ & 37 & 38 \\
\hline 2 & $13 \cdot 6$ & $\mathrm{~F}$ & 4 & $8 \cdot 0$ & $\mathbf{N}$ & $\mathbf{N}$ & 26 & $58 \cdot 5$ & $52 \cdot 5$ & 43 & 49 \\
\hline 3 & $16 \cdot 5$ & $F$ & 3 & $6 \cdot 5$ & Familial & Poor feeder & 30 & $98 \cdot 8$ & $58 \cdot 3$ & 35 & 34 \\
\hline 4 & $20 \cdot 0$ & $\mathrm{~F}$ & 2 & $6 \cdot 0$ & Familial & $\mathbf{N}$ & 40 & $98 \cdot 5$ & $56 \cdot 7$ & 32 & 31 \\
\hline 5 & $9 \cdot 1$ & $\mathbf{M}$ & 2 & $5 \cdot 4$ & ? Toxaemia & Jaundiced & 16 & $42 \cdot 5$ & $48 \cdot 3$ & 36 & 36 \\
\hline 6 & $14 \cdot 1$ & $\mathbf{F}$ & 4 & $7 \cdot 0$ & $\mathbf{N}$ & $\mathbf{N}$ & 22 & $84 \cdot 7$ & $52 \cdot 3$ & 41 & 39 \\
\hline 7 & $16 \cdot 0$ & $\mathbf{F}$ & 6 & $7 \cdot 6$ & $\mathbf{N}$ & $\begin{array}{l}\text { Sucking } \\
\text { difficulty }\end{array}$ & 26 & $70 \cdot 6$ & $54 \cdot 5$ & 38 & 42 \\
\hline 8 & $5 \cdot 6$ & $\mathbf{M}$ & 1 & $7 \cdot 4$ & $\mathbf{N}$ & $\begin{array}{c}\text { 'Blue' } \\
\text { asphyxia }\end{array}$ & 50 & $42 \cdot 0$ & $36 \cdot 5$ & 27 & 25 \\
\hline 9 & $4 \cdot 9$ & $\mathbf{M}$ & 1 & $9 \cdot 0$ & $\mathbf{N}$ & $\mathbf{N}$ & 32 & $28 \cdot 1$ & $31 \cdot 0$ & 23 & 24 \\
\hline 10 & $2 \cdot 9$ & $\mathbf{M}$ & 3 & $6 \cdot 6$ & $\begin{array}{c}\text { Threatened } \\
\text { abortion } \\
3 \mathrm{mth} \text {. }\end{array}$ & $\mathbf{N}$ & 34 & $14 \cdot 8$ & $28 \cdot 0$ & 26 & 29 \\
\hline 11 & $11 \cdot 8$ & $\mathbf{F}$ & 3 & $6 \cdot 2$ & $\mathbf{N}$ & $\mathbf{N}$ & 45 & $70 \cdot 4$ & $54 \cdot 5$ & 36 & 37 \\
\hline Mean & $11 \cdot 3$ & & $2 \cdot 9$ & $7 \cdot 0$ & & & $30 \cdot 8$ & $69 \cdot 2$ & $48 \cdot 4$ & 34 & $34 \cdot 9$ \\
\hline
\end{tabular}

at birth, and another three were 'jaundiced'. Of another four cases (Table 2) with a history of difficulty in sucking, one has been diagnosed as having a ventricular septal defect, pulmonary stenosis and a possible atrial septal defect, one as a ventricular septal defect, pulmonary stenosis and overriding great vessels, the third as a ventricular septal defect and Eisenmenger's syndrome and the fourth as a ventricular septal defect alone. Only three of the 11 cases with congenital heart defect had a normal neonatal history. In six of the 11 cases congenital heart defect was diagnosed at birth.

In the control group one case was cyanosed, one was jaundiced, one was a poor feeder and another had sucking difficulty, while seven had a normal neonatal history. 
Birthweight. The mean birthweight of 76 of the 111 cases without cardiac anomalies was $6.57 \mathrm{lb}$. (Table 1). The mean weight of the 26 cases with cardiac anomalies was $7 \cdot 11 \mathrm{lb}$. (11 clinical cases, with mean birthweight of $7 \cdot 4 \mathrm{lb}$., and 15 autopsied cases, $6.9 \mathrm{lb}$.). These mean differences are statistically significant at the $\cdot 05$ level $(t=2 \cdot 260)$.

Growth and Development. In Table 5 growth and development are compared in the clinical congenital heart defect group and in the controls. The mean age of the congenital heart defect group was $11 \cdot 2$ years, while that of the control group was $11 \cdot 3$ years. The mean weights, 67.6 and $69 \cdot 2 \mathrm{lb}$., and mean heights, 47.5 and 48.4 in., respectively, show that there were no significant differences in these respects between the two groups.

In Tables 3 and 4 similar comparisons are made for the autopsied groups. In Table 4 only 15 of the patients without congenital heart defect had their heights measured at the time of death, the mean being 33.3 in. The age range was from 11 months $(0.9$ year) to 9 years (mean 3.3 years), and the mean weight was $24.7 \mathrm{lb}$. The mean height and weight for the 16 autopsied cases with congenital heart defect was $31 \mathrm{in}$. and $23 \mathrm{lb}$., the mean age being 3.2 years and age range from 1 year to 7 years and 10 months $(7 \cdot 8$ year). Case a. 7 was not included because of age ( 27 years).

Intelligence Quotient. In Table 5 the I.Q. is compared in the clinical congenital heart defect and control groups, both averaging $30 \cdot 8$. In the autopsied groups the I.Q. averages 32 for the congenital heart defect group (Table 3 ) and 31 for the group with normal hearts (Table 4). This finding is consistent with the general opinion that a congenital heart defect has no effect on the intellectual capacity, hence mongolism associated with congenital heart defect still falls within the imbecile range common to the general mongoloid population. However, Mossberger (1949) has shown that heart malformation causing insufficient blood supply to the brain can cause mental retardation.

\section{Discussion}

Among all the possible factors so far postulated relating to the causation of mongolism, advanced maternal age has been most frequently incriminated. Jenkins (1933), Penrose (1934) and Bleyer (1938) all arrived at a critical maternal age of 32 years for the production of mongolism. They attached no importance to the father's age. Lahdensuu (1937) did not agree that maternal age plays a very important part in causing mongolism.
Parents' age in relation to congenital cardiac anomalies in mongolism has not previously been mentioned. In the present series there was no marked difference between parents' ages in the congenital heart defect group and in the group with normal hearts.

Birthweight needs further investigation and more consideration.

Southwick (1939), after comparing the birthweight of mongols and normal infants, concluded that there was no significant difference. On the other hand, Smith and McKeown (1955) found that prematurity was more frequent among mongol infants. A mean birthweight of $6.38 \mathrm{lb}$. for 103 mongols was lower than that of $7 \cdot 10 \mathrm{lb}$. for the 4,931 controls. The former figure is similar to that arrived at in our present analysis of the group with normal hearts, but a mean birthweight of $7 \cdot 11 \mathrm{lb}$. is found in our congenital heart defect group, which is higher than that of their controls.

Taussig (1947), in her chapter on transposition of the great vessels, mentioned that non-mongol infants so affected may have a normal weight curve at birth. In our series this anomaly was not seen. In the present series vessel anomalies were suggested in four cases, for instance, Case 1 in Tab'e 2 had a persistent left superior vena cava, the birthweight being $9 \mathrm{lb}$. Case $10 \mathrm{had}$ an over-riding of the great vessels combined with other anomalies, the birthweight being $6.8 \mathrm{lb}$. In Table 3 Case a.4 had a persistent left superior vena cava combined with ostium secundum, the birthweight being $5.6 \mathrm{lb}$., and in Case a.8 there was a persistence of the sinus venosus combined with a ventricular septal defect, the birthweight being $6.8 \mathrm{lb}$. These give a mean birthweight of $7 \cdot 05 \mathrm{lb}$.

The large percentage of higher birthweights in the congenital heart defect group needs further explanation. Birthweight in general offers significant and valuable information regarding viability and subsequent growth and development. Obviously there are many factors operating in prenatal growth : heredity, maternal health, unusual intrauterine environment, order of birth, etc., may all play some part.

In the present series, a higher birthweight is noted in the mongols with congenital heart defect than in those without. Although the number of cases is small, the high birthweight in both clinical and autopsy groups is significant. As Taussig has said, certain types of congenital heart defect may not affect the intrauterine circulation and consequently play no part in foetal growth. The high birthweight in the congenital heart defect group raises the possibility that the cardiac anomaly may be favour- 
able to foetal growth, but, on the other hand, the increased birthweight may be related to some degree of tissue oedema due to circulatory disturbance. Unfortunately, no studies of subsequent development and rate of growth of the neonatal period have yet been made in this group of patients, so the usual causes of high birthweight cannot be excluded and this highly interesting and controversial finding cannot adequately or satisfactorily be explained.

Davenport and Allen (1925) found a tendency for mongolism to occur in later pregnancies, and in Lahdensuu's (1937) series $28 \cdot 3 \%$ were first-born. Our series shows that there is a slight suggestion of later birth rank in the clinical congenital heart defect group, but among the autopsied cases the birth rank is slightly higher in the group without congenital heart defects. On the other hand, of the 27 cases in the congenital heart defect group, five or $18.5 \%$ were first-born, and in the control groups (11 clinical controls and 22 autopsy cases with normal hearts) six or $18.2 \%$ were first-born. The difference between these two groups is too small for statistical assessment, but it seems reasonable to conclude that there is no evidence of a higher birth rank for mongols with congenital heart disease than for those without.

Table 6 summarizes the different cardiac abnormalities occurring in 27 mongols, but owing to the incidence of multiple lesions in some cases there were 42 defects.

TABLE 6

TYPES OF CONGENITAL CARDIAC DEFECTS FOUND IN 27 MONGOLS

\begin{tabular}{|c|c|c|c|c|}
\hline $\begin{array}{c}\text { Types of Congenital Cardiac } \\
\text { Anomalies }\end{array}$ & \multirow{2}{*}{$\begin{array}{c}\text { Clinical } \\
\text { Group } \\
6 \\
4 \\
1 \\
2 \\
3 \\
1\end{array}$} & $\begin{array}{c}\begin{array}{c}\text { Autopsy } \\
\text { Group }\end{array} \\
4 \\
4 \\
6 \\
2\end{array}$ & \multicolumn{2}{|c|}{$\begin{array}{l}\text { Total No. of } \\
\text { Lesions } \\
\text { (No.) (\%) }\end{array}$} \\
\hline 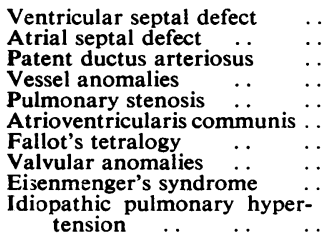 & & \begin{tabular}{|l|}
4 \\
4 \\
6 \\
2 \\
2
\end{tabular} & $\begin{array}{r}10 \\
8 \\
7 \\
4 \\
3 \\
3 \\
2 \\
2 \\
2\end{array}$ & $\begin{array}{r}24 \\
19 \\
17 \\
9 \\
7 \\
7 \\
5 \\
5 \\
5\end{array}$ \\
\hline Total & & & 42 & 100 \\
\hline
\end{tabular}

The result of the present survey agrees with Leech's (1935) observation that persistent atrioventricularis communis is not the most common cardiac anomaly in mongolism in the age ranges studied, and supports Evans' finding that ventricular septal defect is the most common, atrial septal defect the second, and patent ductus arteriosus the third in frequency. Others, such as vessel anomalies, pulmonary stenosis, atrioventricularis communis,
Eisenmenger's syndrome and Fallot's tetralogy, etc. are less common.

\section{Summary}

Congenital heart disease has been studied in a group of 173 mongoloid imbeciles admitted to the Fountain Hospital during a period of 14 years. Fifty-one died and autopsies were performed on 44 of them (mean age $3 \cdot 3$ years), $36 \cdot 4 \%$ (16/44) showing congenital heart defects. Of the 122 patients still in hospital (mean age 10 years), 9\% (11/122) have proved to have congenital heart defects.

The high proportion of maternal illness in the congenital heart defect group suggests that maternal health during pregnancy may have a direct bearing on the heart malformation.

No difference was found in parental age and birth rank between the groups with and without congenital heart defect.

Higher birthweights and no prematurity were found in the mongols with congenital heart disease.

Congenital heart defect has no influence on the I.Q.

Ventricular and atrial septal defects are the commonest congenital heart anomalies in mongolism.

We wish to express our thanks to the Physician Superintendent and the Director of the Research Committee of the Fountain Hospital for their permission to undertake this study, and to Dr. A. Leatham and his colleagues in the Cardiac Department of St. George's Hospital for all their help. Our thanks are due also to our Pathology Department for allowing us free use of their autopsy material and notes, to all our colleagues for their constant encouragement and helpful criticism, and to the Medical Records Department for their cordial co-operation.

\section{REFERENCES}

Abbott, M. E. (1936). Atlas of Congenital Cardiac Disease. American Heart Association, New York.

Benda, C. E. (1946). Mongolism and Cretinism. Grune and Stratton, New York.

Bleyer, A. (1938). Amer. J. Dis. Child., 55, 79.

Davenport, C. B. and Allen, G. (1925). J. Psycho-Asthenics., 29, 266.

Engler, M. (1949). Mongolism, p. 48. Wright, Bristol.

Esen, F. M. (1957). Arch. Pediat., 74, 243.

Evans, P. R. (1950). Brit. Heart J., 12, 258.

Gregg, N. M. (1941). Trans. ophthal. Soc. Aust., 3, 35. Babbott, J. and Philbrook, R. (1957). Amer. J. Obstet. Gynec., 74, 572 .

Jenkins, R. L. (1933). Amer. J. Dis. Child., 45, 506.

Keith, J. D., Rowe, R. D. and Vlad, P. (1958). Heart Disease in Infancy and Childhood. The MacMillan Co., London.

Lahdensuu, S. (1937). Acta paediat. (Stockh.), 21, 256.

Leech, C. B. (1935). J. Pediat., 7, 802.

Mossberger, J. I. (1949). Amer. J. Dis. Child., 78, 28.

Penrose, L. S. (1934). Proc. roy. Soc. B., 115, 431.

Smith, A. and McKeown, T. (1955). Archives of Disease in Childhood, 30, 257.

Southwick, W. E. (1939). Amer. J. Dis. Child., 57, 68.

Swan, C., Tostevin, A. L., Moore, B., Mayo, H., and Black, G. H. B. (1943). Med. J. Aust., 2, 201.

Taussig, H. B. (1947). Congenital Malformation of the Heart. Oxford University Press. 